\title{
Role of volatile and contact pheromones in the mating behaviour of Bagrada hilaris (Heteroptera: Pentatomidae)
}

\author{
Salvatore GUARinO ${ }^{1}$, Claudio De PASQUale ${ }^{2}$, Ezio PERI ${ }^{1}$, Giuseppe AlONZO ${ }^{2}$ and Stefano COLAZZA ${ }^{1 *}$ \\ ${ }^{1}$ Department of S.En.Fi.Mi.Zo., Section of Acarology, Entomology and Zoology, Università di Palermo, Viale delle Scienze 13, \\ 90128 Palermo, Italy; e-mail: colazza@unipa.it \\ ${ }^{2}$ Department of I.T.A.F., Università di Palermo, Viale delle Scienze 13, 90128 Palermo, Italy
}

Key words. Heteroptera, Pentatomidae, Bagrada hilaris, Painted bug, vertical open Y-shaped olfactometer, air collection, GC-MS, pheromone

\begin{abstract}
Volatiles and contact pheromones involved in the mating behaviour of the Painted bug, Bagrada hilaris Burmeister (Heteroptera: Pentatomidae), were investigated in behavioural and chemical experiments. Vertical open Y-shaped olfactometer bioassays showed that odour from males attract females but not males, while that from females did not attract either gender. Adult females were also attracted by hexane extracts of volatile compounds collected from males. In open arena bioassays, males displayed the characteristic steps of courtship behaviour in the presence of virgin females. Such courtship behaviour was displayed in the presence of females killed by freezing, but not in the presence of freeze-killed females washed with hexane. Gas chromatography-mass spectrometry (GC-MS) analysis of volatile compounds produced by cohorts of $20 \mathrm{~B}$. hilaris adults and collected over $48 \mathrm{~h}$ showed that both males and females produce the compounds nonanal, decanal and $(E)$-2-octenyl acetate. Of these compounds males produce significantly more $(E)$-2-o-octenyl acetate, i.e. $186.74 \mathrm{ng}$ and $67.53 \mathrm{ng}$ for males and females respectively. These findings indicate this compound is possibly a long range volatile pheromone, and a complex lipophilic fraction of the adult cuticle possible contact pheromone involved in short range courtship behaviour.
\end{abstract}

\section{INTRODUCTION}

Mating behaviour in insects can be divided into two main phases, long-range mate location and close-range courtship (Thornhill \& Alcock, 1983). Long-range mate location is the upwind orientation and approach of one sex towards the other, which brings the two sexes into close proximity; while close-range courtship is the interaction of both sexes when in close proximity, which can result in copulation (Thornhill \& Alcock, 1983; Wertheim et al., 2005).

Studies on phytophagous species of Heteroptera show that the long-range mate location is mediated by sex and/or aggregation pheromones, consisting of a mixture of volatile chemicals, mainly esters, terpenoids and alcohols (Aldrich, 1996; Miklas et al., 2000). In many cases, pheromone compounds are produced only by one gender, as in Nezara viridula L., Euschistus spp., Plautia stali Scott, Thyanta pallidovirens Stal, Piezodorus hybneri Gmelin, Biprorulus bibax Breddin, Chlorochroa sayi Stal, Thyanta perditor F., Thyanta pallidovirens Stal and Murgantia histrionica Hahn (Baker et al., 1987; Aldrich et al., 1991, 1994; Brezot et al., 1994; James et al., 1994; Sugie et al., 1996; Millar, 1997; Borges et al., 1998; Leal et al., 1998; Ho \& Millar 2001a; McBrien et al., 2002; Moraes et al., 2005; Zahn et al., 2008). In other cases, pheromones are produced by both sexes but with different gender-specific relative abundances, as in Geocoris punctipes Say and Leptocorisa chinensis Dallas (Leal et al., 1996; Marques et al., 2000). Once males and females are in close proximity, cues such as visual (Capone, 1995), acoustic (Cade, 1985) and/or close range contact pheromones (Ginzel et al., 2003) are involved in triggering the courtship behaviour. Studies on the close-range courtship behaviour of true bugs reveal the presence of specific behavioural steps, from contact to copulation, indicating that behavioural postures and chemical stimuli are implicated in successful mate recognition (Borges et al., 1987; Ho \& Millar, 2001a). As is the case of the cuticular hydrocarbons that are responsible for the gender recognition in several species of non-social insects belonging to the orders Dyctioptera (Nojima et al., 1999), Coleoptera (Ginzel et al., 2003) and Diptera (Carlson et al., 1998). In some cases males and females produce different hydrocarbons, as in Megacyllene cariae Gahan (Ginzel et al., 2006), or the same hydrocarbons, but in gender-specific relative abundances, as in Drosophila spp. (Toolson \& Kuper-Simbron, 1989; Cobb \& Ferveur, 1996).

Bagrada hilaris (Burmeister), the commonly named Painted bug, is a pest of Cruciferous crops throughout Asia, Africa and on some islands of southern Europe such as Malta and Pantelleria (Italy) (CAB, 1981). On Pantelleria, Painted bug attacks caper plants, Capparis spinosa L., damaging leaves, stems and flower buds (Colazza et al., 2004). B. hilaris populations are usually sprayed annualy with 4-5 applications of pesticide, (Colazza et al., 2004). As a consequence, adults of $B$. hilaris are slowly becoming resistant to pesticides (Swaran Dhingra \& Seema, 1998; Guarino et al., 2007).

\footnotetext{
* Corresponding author.
} 
Little information is available on the chemical compounds involved in the mating behaviour of $B$. hilaris. Previous studies on the composition of the cuticular hydrocarbons of the Painted bug revealed linear and branched hydrocarbons, which are qualitatively similar, but present in different quantities in the two genders (De Pasquale et al., 2007). However, the significance of these quantitative differences in the mating behaviour is not defined. The main objectives of this study were to characterize the volatile pheromones used in long range mate location and the cues involved in the close range courtship of B. hilaris.

\section{MATERIAL AND METHODS}

\section{Insects}

A colony of $B$. hilaris was established and restocked regularly with insects collected from May to November 2006 from caper fields located on the island of Pantelleria. The insect colony was maintained on caper buds, cole-seed and cabbage depending on seasonal availability. Food was changed every 2-3 days. All stages were reared in an environmentally controlled room $(25 \pm$ $1^{\circ} \mathrm{C}, 70 \pm 10 \%$ R.H., photoperiod $\left.16 \mathrm{~L}: 8 \mathrm{D}\right)$, inside wooden cages $(25 \times 25 \times 40 \mathrm{~cm})$ with two 5 -cm $\varnothing$ mesh-covered holes for ventilation. Separate rearing cages were used for nymphs and adults.

\section{Collection of volatiles produced by adults}

Cohorts of 20 virgin adult $B$. hilaris of the same sex and age (about 5 days old) and caper flower buds (used as food) were put into an horizontal all-glass apparatus 11 in volume. Humidified and charcoal filtered air was drawn through the chambers (flow $0.41 \mathrm{~min}^{-1}$ ). Bugs were transferred carefully into the chambers to avoid the discharge of defensive secretions and were exposed to the air flow for $48 \mathrm{~h}$ at $25 \pm 2{ }^{\circ} \mathrm{C}$. The volatiles were trapped in glass collectors $(6 \mathrm{~mm}$ ID) filled with $70 \mathrm{mg}$ of 18-35 mesh activated charcoal (Merck KGaA, Darmstadt, Germany) held in place by glass wool plugs. Collectors were prepared a few minutes before the start of a collection, then, at the end of the aeration period, were eluted with hexane $(200 \mu \mathrm{l})$. The elutes were stored at $-18^{\circ} \mathrm{C}$ until subjected to GC-MS analyses or used in the vertical open Y-shaped olfactometer bioassays. The experiments were done close to a window which provide a source of natural daylight, and two fluorescent light bulbs (Lival, 220V-11W, Finland) controlled by a timer located above the horizontal all-glass aeration apparatus to provide supplementary light source with a $16 \mathrm{~L}: 8 \mathrm{D}$ photoperiod.

\section{Chemical analyses}

GC-MS analyses were performed using a Hewlett-Packard 5890 GC system interfaced with an HP 5973 quadrupole mass spectrometer detector. As a stationary phase an HP5-MS capillary column (5\% diphenyl - 95\% dimethylpolysiloxane $30 \mathrm{~m}$ $0.2 \mathrm{~mm}, 0.25 \mu \mathrm{m}$ film thickness, J\&W Scientific, USA) was used. Injector and detector temperatures were $250^{\circ} \mathrm{C}$ and $270^{\circ} \mathrm{C}$ respectively. Helium was used as the carrier gas. The GC oven temperature program was $40^{\circ} \mathrm{C}$ for $5.00 \mathrm{~min}$, than increased by $10^{\circ} \mathrm{C} / \mathrm{min}$ to $280^{\circ} \mathrm{C}$. Electron impact ionization spectra were obtained at $70 \mathrm{eV}$, recording mass spectra from 42 to 550 uma. Compound identification was carried out using a commercial NIST 98 mass spectra library search and by comparison with standard analytical grade compounds purchased from SigmaAldrich (USA). [The syntethic (E)-2-octenyl acetate was kindly provided by Prof. J.G. Millar.] Quantitative analysis was carried out only for $(E)$-2-octenyl acetate, the putative pheromone of this bug. For this analysis the elutes were diluted in $1 \mathrm{ml}$ of hexane using a volumetric flask. Five point calibration curves in the $1-50 \mathrm{ng} \mu \mathrm{l}^{-1}$ range were used in order to evaluate the chromatographic response. Then, analytical extraction recovery experiments of $(E)$-2-octenyl acetate were carried out using 10 $\mu \mathrm{l}$ of hexane solutions $\left(100 \mathrm{ng} \mu \mathrm{l}^{-1}\right)$ of the synthetic standard spotted on a disk of filter paper ( $3 \mathrm{~cm}$ diameter), placed inside the aeration apparatus described above, and aerated for $1 \mathrm{~h}$ (flow $0.41 \mathrm{~min}^{-1}$ ).

\section{Vertical open Y-shaped olfactometer bioassays}

Olfactory orientation evoked by volatiles of different origin was investigated using a vertical open Y-shaped olfactometer, which is a modification of the apparatus described by Visser \& Piron (1998). Unlike to their olfactometer, the brass rod has an outer diameter of $5 \mathrm{~mm}$, the length of the central wire stem is 16 $\mathrm{cm}$ and the flow rate was $0.41 \mathrm{~min}^{-1}$. Two glass chambers $(125$ $\mathrm{ml}$ ) were used as the odour source holders, and during the different tests, at every fourth replicate, the odour sources were interchanged in order to avoid bias. At every switch, all the glass parts of the apparatus were washed with water and detergent, and then wiped with acetone and the brass rod cleaned with distilled water and acetone. After each experiment, the apparatus was cleaned with distilled water and acetone and oven dried for at least $20 \mathrm{~min}$ at $150^{\circ} \mathrm{C}$. Light was provided by an electric lamp (Osram, 12V-35W, Germany) suspended $30 \mathrm{~cm}$ above the olfactometer. Bioassays were conducted at $25 \pm 2{ }^{\circ} \mathrm{C}$ and $50 \pm 15 \%$ R.H. A single $B$. hilaris adult was carefully released at the bottom of the central stem of the olfactometer and allowed $15 \mathrm{~min}$ to respond. The first choice of the bug was recorded once the insect moved into one arm $5 \mathrm{~cm}$ past the junction. Bugs that didn't move into one of the two arms during the $15 \mathrm{~min}$ trial were scored as non responders and not included in the analysis.

The first experiments are carried out to determine the olfactory reactions of males and females of $B$. hilaris to the odour released by the same or opposite gender. The insects used for this experiment were sexed and kept separated for 3-4 days before the test. A group of 8 virgin 5-days-old sexually mature adults was placed in the glass chamber, while the other glass chamber was left empty as a control. The group of bugs used as the stimulus source was changed after each four replicates. The following four combinations were tested: males responding to female odour $(N=33)$, males responding to male odour $(N=$ $34)$, females responding to female odour $(N=34)$, females responding to male odour $(N=32)$.

A second set of experiments was used to determine the olfactory response of females to hexane extracts of volatile compounds collected from male adults, as previously described. An aliquot of $1 \mu 1$ of the extract was spotted on a disk of filter paper ( $2 \mathrm{~cm}$ diameter). The solvent was allowed to evaporate for 2 min. The control chamber was supplied with a filter paper disk ( $2 \mathrm{~cm}$ diameter) treated with $1 \mu 1$ of hexane. Only sexually mature virgin females ( $>5$ days old, $N=11$ ) were tested in this bioassay, using, as the odour source, male extract obtained from a $48 \mathrm{hr}$ aeration of a cohort of 20 male bugs.

\section{Petri dish arena bioassays}

Bioassays were carried out using a $5 \mathrm{~cm}$ diameter Petri dish as an arena, which was monitored by a Hitachi KP-D40 colour digital video camera connected to a Sharp VC-GH600SM VHS videocassette recorder. Insects used in this experiment were sexed and kept separate for 3-4 days before being tested. Virgin adult pairs of Painted bug were put individually in the Petri dish arena and recorded for $20 \mathrm{~min}(N=22)$. Then, the different phases in the courtship were defined and their duration determined with the aid of a stop watch. 


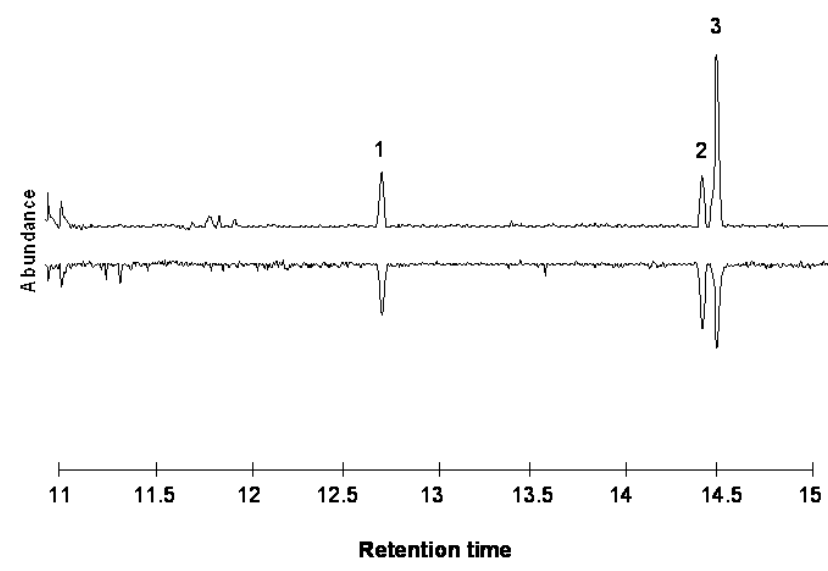

Fig. 1. Gas chromatograms of the volatile compounds collected from cohorts of $20 \mathrm{~B}$. hilaris adults over a period of $48 \mathrm{~h}$. Males (top) and females (bottom, inverted). 1 - nonanal; 2 decanal; $3-(E)$-2-octenyl acetate.

In order to demonstrate that males of $B$. hilaris recognize females using a contact pheromone, females were killed by freezing $\left(-18^{\circ} \mathrm{C}\right.$ for $\left.30 \mathrm{~min}\right)$ and then treated with different solvents or not as described below. After being killed by freezing, untreated females were allowed to warm up at room temperature and then presented to a male. The male's behaviour was recorded for $20 \mathrm{~min}$, and scored as a positive response if it displayed courtship behaviour for more then $10 \mathrm{~s}$ after contacting the female with its antennae. This experiment was replicated 10 times. To determine the chemical fractions involved in mate recognition, freeze-killed females were immersed for $2 \mathrm{~h}$ in $2 \mathrm{ml}$ of one of three solvents with different polarity: hexane, ethyl acetate or distilled water. Each treated female was exposed to a single male and the behaviour recorded as previously described. This experiment was replicated 10 times for each solvent.

\section{Statistical analysis}

Data on the number of responses of males and females to different treatments (live insects and air collected extracts versus controls) were analyzed using a $\chi^{2}$ goodness of fit test (Sokal \& Rohlf, 1995). The interest shown by male bugs towards females washed with different solvents was also analyzed using a $\chi^{2}$ goodness of fit test (Sokal \& Rohlf, 1995). While, the quantitative analysis of the differences in the amount of $(E)$-2-octenyl acetate recovered from males and females were compared using a $t$-test (Sokal \& Rohlf, 1995). All the statistical analyses were performed using Statistica for Windows 6.0 (Stat Soft Italia, 1997).

\section{RESULTS}

\section{Chemical analyses of adult volatiles}

Main peaks of typical gas chromatograms of the aeration extracts of females and males of $B$. hilaris are shown in Fig. 1. Comparison of these extracts using GC-MS analyses revealed the same compounds as nonanal, decanal and (E)-2-octenyl acetate (Fig. 1). Quantitative analysis of $(E)$-2-octenyl acetate indicated that males produced an higher amount of this compound, i.e. groups of 20 males of $B$. hilaris produced an average of $186.74 \mathrm{ng}$ per $48 \mathrm{~h}$ compared to the $67.53 \mathrm{ng}$ produced by 20 females $(\mathrm{t}=-3.17 ; N=5 ; \mathrm{P}=0.013)$.

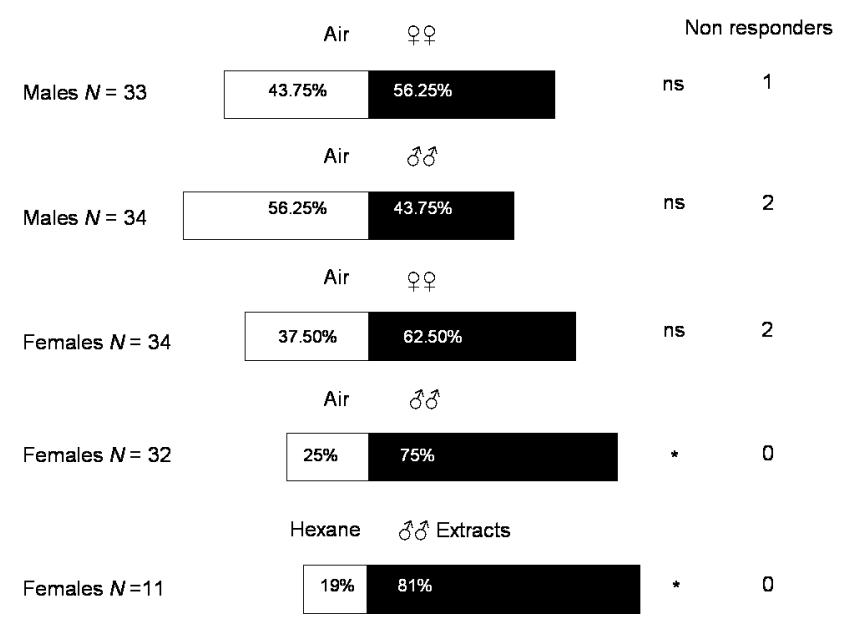

Fig. 2. First choice response (\%) of B. hilaris adults in a vertical open Y-shaped olfactometer to different treatments. ${ }^{*}=\mathrm{P}$ $<0.05 ; \mathrm{ns}=$ not significantly different $\left(\chi^{2}\right.$ test). $N=$ number of replicates.

\section{Vertical open Y-shaped olfactometer bioassays}

The results of the vertical open Y-shaped olfactometer bioassays are shown in Fig. 2. Females of $B$. hilaris were more attracted to the odour from live males than from the control $\left(\chi^{2}=8 ; N=32, \mathrm{P}=0.05\right)$. Females were not attracted to the odour of females $\left(\chi^{2}=2 ; N=34, \mathrm{P}>\right.$ $0.05)$ and males showed no preference for either the odour of females $\left(\chi^{2}=0.5 ; N=33, \mathrm{P}>0.05\right)$ or males $\left(\chi^{2}\right.$ $=0.5 ; N=34, \mathrm{P}>0.05)$. Furthermore, females responded to the crude extract of males odour obtained from the air that passed over the males $\left(\chi^{2}=4.45, N=11, \mathrm{P}=0.03\right)$.

\section{Petri dish arena bioassays}

The courtship behaviour that preceded copulation was divided into three phases. In the first phase, "contact phase", males antennate a female's body; in the second "mount-antennation phase", males mount a female and start to antennate the female's antennae and genitalia. Finally, in the "engagement" phase the male dismounts and start to copulate by putting his last pair of legs on the female's abdomen and coupling his genitalia with those of the female. For each phase the average time ( \pm SD) was: $1.12 \pm 0.93 \mathrm{~s}$ for contact, $14.78 \pm 8.41 \mathrm{~s}$ for mountantennation and $41.85 \pm 18.31 \mathrm{~s}$ for engagement. After the contact phase, if the female was receptive, she adopted a posture with her head slightly lowered and abdomen raised, to allow the male to mate. Mating took place in about $77 \%$ of the replicates $(N=22)$. During mating, both female and male bugs stood in an end to end position, with their abdomens higher than their heads. Once copulation was complete one of the bugs swung from side to side to disengage from the other.

In the experiment with freeze-killed females of $B$. hilaris, males always attempted to mate unwashed cadavers $(N=10)$. After contacting cadavers treated with different solvents, $90 \%$ of the males attempted to mate with females previously washed in distilled water $\left(\chi^{2}=\right.$ $0.1 ; N=10, \mathrm{P}>0.05) ; 40 \%$ when the females were washed in ethyl acetate $\left(\chi^{2}=3.6 ; N=10, \mathrm{P}>0.05\right)$ and 
only $20 \%$ when washed in hexane $\left(\chi^{2}=6.4 ; N=10, \mathrm{P}=\right.$ 0.01 )

\section{DISCUSSION AND CONCLUSIONS}

The results of the vertical open Y-shaped olfactometer bioassays showed that females were attracted to odours produced by male and similarly attracted to a solvent extract of males volatiles. Chemical analysis of the odours of the two sexes of Painted bug indicated they are qualitatively similar. Quantitative analysis indicated that the odour of males contained more $(E)$-2-octenyl acetate than that of females. This suggest that females locate males from a distance partly or wholly by responding to (E)-2-octenyl acetate. This compound is also used as a sex and/or aggregation pheromone by other heteropteran species (Leal et al., 1996; Marques et al., 2000). For example, in the lygaeid $G$. punctipes, $(E)$-2-octenyl acetate is produced mainly from females and it plays a role as sex pheromone (Marques et al., 2000). Furthermore, in the alydid $L$. chinensis, a blend of $(E)$-2-octenyl acetate and octenol is produced by both sexes, but it is only attractive to males (Leal et al., 1996). Of the other chemical compounds in the Painted bug air collections, nonanal and decanal are commonly produced by other true bugs species (Borges et al., 2006). Further laboratory and field experiments are needed to determine the full role of $(E)$-2-octenyl acetate in the ecology of this species.

The close range courtship behaviour of the Painted bug is similar to that described for other species of true bugs, e.g. N. viridula, and C. sayi (Borges et al., 1987; Ho \& Millar, 2001b). However, B. hilaris males showed a specific kind of mount and antennation of the female's antennae and genitalia, and they did not head butt the posterior end of females. The results of the Petri dish arena bioassays, using cadavers of females, indicate that males of the Painted bug recognize the opposite sex mainly by antennation of her cuticular surface. All the Painted bug males attempted to mate with cadavers of females, suggesting that the recognition was not cued only by mechanoreception or visual stimuli. The fact that the active compounds were partially removed by hexane, suggests that sex recognition is based on chemical cues in which the lipophilic fraction plays the main role. The role of cuticular hydrocarbons as contact pheromones in inducing close range courtship behaviour is described for species of Coleoptera (Ginzel et al., 2003; OrtizDomínguez et al., 2006; Ginzel et al., 2006), Diptera (Uebel et al., 1975; Carlson et al., 1984) and Hymenoptera (Howard \& Baker, 2003). In B. hilaris the difference in the relative abundance of the cuticular hydrocarbons of males and females (De Pasquale et al., 2007), might mediate gender recognition in this species.

ACKNOWLEDGEMENTS. This study was financially supported by the project "Caratterizzazione, Miglioramento genetico-sanitario e Difesa del cappero (Capparis spinosa L.) delle isole minori della Sicilia" funded by Regional Agricultural Bureau of Sicilian Region - IX Servizio allo Sviluppo, Unità
Operativa 45 - Sperimentazione e Ricerca Applicata (L. 499/99).

\section{REFERENCES}

AldRICH J.R. 1996: Sex pheromones in Homoptera and Heteroptera. In Schaefer C.W. (ed.): Studies on Hemipteran Phylogeny. Entomological Society of America, Thomas Say Publications, Lanham, Maryland, pp. 199-226.

Aldrich J.R., Hoffman M.P., Kochansky J.P., Lusby W.R., Eger J.E. \& PAYNE J.A. 1991: Identification and attractiveness of a major pheromone component for neartic Euschistus spp. Stink bug (Heteroptera: Pentatomidae). Environ. Entomol. 20: 477-483.

Aldrich J.R., Numata H., Borges M., Bin F., Waite G.K. \& LusBY W.R. 1994: Identification of male specific volatiles from neartic and neotropical stink bugs (Heteroptera: Pentatomidae). J. Chem. Ecol. 20: 1103-1111.

Baker R., Borges M., Cooke N.G. \& Herbert R.H. 1987: Identification and synthesis of (Z)-(1'S,3'R,4'S)(-)-2-(3',4'epoxy-4'methylcycloexyl)-6-methylhepta-2,5-diene, the sex pheromone of the Southern Stink Bug, Nezara viridula, L., (Heteroptera: Pentatomidae). J. Chem. Soc. Chem. Comm. 414-416.

Borges M., Jepson P.C. \& Howse P.E. 1987: Long range mate location and close range courtship behaviour of the green stink bug, Nezara viridula and its mediation by sex pheromones. Entomol. Exp. Appl. 44: 205-212.

Borges M., Schmidt F.G.V., Suji E.R., Medeiros M.A., Mori K., Zarbin P.H.G. \& Ferreira J.T.B. 1998: Field response of stink bugs to the natural and synthetic pheromone of the Neotropical brown stink bug, Euschistus heros (Heteroptera: Pentatomidae). Physiol. Entomol. 23: 202-207.

Borges M., Birkett M., Aldrich J.R., Oliver J.E., Chiba M., Murata Y., Laumann R.A., Barrigossi J.A., Pickett J.A. \& Moraes M.C.B. 2006: Sex attractant pheromone from the rice stalk stink bug, Tibraca limbaventris Stal. J. Chem. Ecol. 32: 2749-2761.

Brezot P., Malosse C., Mori K. \& Renou M. 1994: Bisabolene epoxides in sex pheromone in Nezara viridula L. (Heteroptera: Pentatomidae): role of cis isomer and relation to specificity of pheromone. J. Chem. Ecol. 20: 3133-3147.

CAB International 1981: Bagrada hilaris. Distribution map. Distribution Maps of Plant Pests. Map 417.

CADE W.H. 1985: Insect mating and courtship behaviour. In Kerkut L.I. \& Gilbert G.A. (eds): Comprehensive Insect Physiology Biochemistry and Pharmacology. Vol. 13. Pergamon Press, Oxford, pp. 591-619.

CAPONE T. 1995: Mutual preference for larger mates in green stink bugs Acrosternum hilare (Heteroptera: Pentatomidae). Anim. Behav. 49: 1335-1344.

Carlson D.A., Nelson D.R., Langley P.A., Coates T.W., Davis T.L. \& Leegwater Vander Linden M. 1984: Contact sex pheromone in the tsetse flies Glossinia pallidipes Austen: identification and synthesis. J. Chem. Ecol. 19: 429-450.

Carlson D.A., Offor I.I., El Messoussi S., Matsuyama K., Mori K.J. \& JALlON M. 1998: Sex pheromone of Glossina tachinoides: isolation, identification, and synthesis. J. Chem. Ecol. 24: 1563-1575.

CobB M. \& Ferveur J.F. 1996: Evolution and genetic control of mate recognition and stimulation in Drosophila. Behav. Proc. 35: 35-54.

Colazza S., Guarino S. \& Peri E. 2004: Bagrada hilaris (Burmeister) (Heteroptera: Pentatomidae) fitofago dannoso al cappero nell'isola di Pantelleria. Inf. Fitopatol. 12: 30-34. 
De Pasquale C., Guarino S., Peri E., Alonzo G. \& Colazza S. 2007: Investigation of cuticular hydrocarbons from Bagrada hilaris genders by SPME/GC-MS. Anal. Bioanal. Chem. 389: 1267-1281.

Ginzel M.D., Blomeuist G.J., Millar J.G. \& Hanks L.M. 2003: Role of contact pheromones in mate recognition in Xylotrechus colonus. J. Chem. Ecol. 29: 533-545.

Ginzel M.D., Moreira J.A., Ray A.M., Millar J.G. \& Hanks L. M. 2006: (Z)-9-nonacosene-major component of the contact sex pheromone of the beetle Megacyllene caryae. J. Chem. Ecol. 32: 435-451.

Guarino S., Peri E., Lo Bue P., La Pillo A. \& Colazza S. 2007: Impiego di insetticidi di origine vegetale per il contenimento delle popolazioni di Bagrada hilaris nei cappereti panteschi. Inf. Fitopatol. 7-8: 53-58.

Ho H.Y. \& Millar J.G. 2001a: Compounds in metathoracic glands of adults and dorsal abdominal glands of nymphs of the stink bugs, Chlorochroa uhleri, C. sayi, and C. ligata (Hemiptera: Pentatomidae). Zool. Stud. 40: 193-198.

Ho H.Y. \& Millar J.G. 2001b: Identification and synthesis of a male produced sex pheromone from the stink bug Chlorochroa sayi. J. Chem. Ecol. 27: 1177-1201.

HOWARD R.W. \& BAKER J.E. 2003: Cuticular hydrocarbons and wax esters of the ectoparasitoid Habrobracon hebetor: ontogenetic, reproductive and nutritional effects. Arch. Insect Biochem. Physiol. 53: 1-18.

James D.G., Mori K., Aldrich J.R. \& Oliver J.E. 1994: Flightmediated attraction of Biprorulus bibax Breddin (Hemiptera: Pentatomidae) to natural and synthetic aggregation pheromone. J. Chem. Ecol. 20: 71-80.

Leal W.S., UedA Y. \& ONo M. 1996: Attractant pheromone for male rice bug Leptocorisa chinensis: semiochemicals produced by both male and female. J. Chem. Ecol. 22: $1429-1437$

Leal W.S., Kuwahara S., Shi X., Higuchi H., Marino C.E.B., Ono M. \& Meinwald J. 1998: Male released sex pheromone of the stink bug Piezodorus hybneri. J. Chem. Ecol. 24: $1817-1829$

Marques F.D.M., Mc Elfresh J.S. \& Millar J.G. 2000: Female produced sex pheromone of the predatory bug Geocoris punctipes. J. Chem. Ecol. 26: 2843-2855.

McBrien H.L., Millar J.C., Rice R.E., Mc Elfresh J.S., Cullen E. \& ZALOM F.G. 2002: Sex attractant pheromone of the redshouldered stink bug Thyanta pallidovirens: a pheromone blend with multiple redundant components. J. Chem. Ecol. 28: 1797-1818.

Miklas N., Renou M., Malosse I. \& Malosse C. 2000: Repeatability of pheromone blend composition in individual males of the southern stink bug, Nezara viridula. J. Chem. Ecol. 26: 2473-2485.

Millar J.G. 1997: Methyl (2E, 4Z, 6Z)-deca-2,4,6-trienoate, a thermally unstable, sex specific compound from the stink bug Thyanta pallidovirens. Tetrahedron 38: 7971-7972.
Moraes C.B.M., Millar J.G., Laumann R.A., Sujit E.R., Pires C.S.S. \& Borges M. 2005: Sex attractant pheromone from the neotropical red-shouldered stink bug Thyanta perditor (F.). $J$. Chem. Ecol. 31: 1415-1427.

Nojima S., Sakuma M., Nishida R. \& Kuwahara Y. 1999: A glandular gift in the german cockroach, Blattella germanica (L.) (Dictyoptera: Blattellidae): the courtship feeding of a female on secretions from male tergal glands. J. Insect Behav. 12: $627-640$.

Ortiz-Domínguez M., Favilla M.E., Mendoza-López M.R., García-Barradas O. \& Cruz-Sánchez J.S. 2006: Epicuticular compounds and sexual recognition in the ball-roller scarab, Canthon cyanellus cyanellus. Entomol. Exp. Appl. 119: 23-27.

SoKal R.R. \& RohlF F.J. 1995: Biometry. 3rd ed. W.H. Freeman, New York, 887 pp.

Statsoft Italia 1997: Statistica per Windows. User's Manual. Statsoft Italia, Vigonza.

Sugie H., Yoshida M., Kawasaki K., Noguchi H., Moritya S., Takagi K., Fukuda H., Fujie A., Yamanaka M., Ohira Y., Tsutsumi T., Tsuda K., Fukumoto K., Yamashita M. \& SUzUKI H. 1996: Identification of the aggregation pheromone of the brown winged green bug, Plautia stali Scott (Hemiptera: Pentatomidae). Appl. Entomol. Zool. 31: 427-431.

Swaran Dhingra \& Seema 1998: Relative toxicity of some important insecticides with particular reference to change in susceptibility level of Bagrada cruciferarum Kirk. during the last quarter century. J. Entomol. Res. 22: 307-311.

THORNHILL R. \& AlCOCK J. 1983: The Evolution of Insect Mating Systems. Harvard University Press, Cambridge, Massachusetts, $547 \mathrm{pp}$.

ToOLSON E.C. \& Kuper-Simbron R. 1989: Laboratory evolution of epicuticular hydrocarbons composition and cuticular permeability in Drosophila pseudoobscura: effects on sexual dimorphism and thermal acclimation ability. Evolution 43: 468-473.

Uebel E.C., Sonnet P.E., Miller R.W. \& Beroza M. 1975: Sex pheromone of the face fly Musca autumnalis De Geer (Diptera: Muscidae). J. Chem. Ecol. 1: 195-202.

VISSER J.H. \& PIRON G.M. 1998: An open Y-track olfactometer for recording of aphid behavioural responses to plant odours. Exp. Appl. Entomol. 9: 41-46.

Wertheim B., Van Baalen E.A., Dicke M. \& Vet L.E.M. 2005: Pheromone-mediated aggregation in nonsocial arthropods: an evolutionary ecological perspective. Annu. Rev. Entomol. 50: 321-346.

ZAHN D.K., Moreira J.A. \& Millar J.G. 2008: Identification, synthesis and bioassays of a male specific aggregation pheromone from the Harlequin bug Murgantia histrionica. J. Chem. Ecol. 34: 238-251.

Received March 27, 2008; revised and accepted May 26, 2008 